\title{
Social networking mobile apps framework for organizing and facilitating charitable and voluntary activities in Malaysia
}

\author{
Salama A. Mostafa' ${ }^{1}$ Aida Mustapha², Palaniappan Shamala ${ }^{3}$, Omar Ibrahim Obaid ${ }^{4}$, \\ Bashar Ahmed Khalaf \\ ${ }^{1,2,3,5}$ Faculty of Computer Science and Information Technology, Universiti Tun Hussin Onn Malay sia, Malay sia \\ ${ }^{4}$ Department of Computer, College of Education, Al-Iraqia University, Iraq \\ ${ }^{5}$ University of Diy ala, Iraq
}

\begin{tabular}{|c|c|}
\hline Article Info & ABSTRACT \\
\hline Article history: & \multirow{9}{*}{$\begin{array}{l}\text { Numerous non-profit driven establishments depend on volunteers to help } \\
\text { achieve their administrative targets. Despite the fact that volunteers work } \\
\text { side-by-side or now and again substitute representatives in delivering services, } \\
\text { inputting volunteer work into non-profit ventures of delivering services } \\
\text { presents remarkable difficulties. Understanding these difficulties provides } \\
\text { a significant fundamental building step in comprehending the influence these } \\
\text { challenges have on service developmental plans and operations when utilizing } \\
\text { volunteers. In this study, the paper bring forward a Charity Fundraising } \\
\text { Information Sy stem (CFIS) framework and presents the modelling } \\
\text { and evaluation of a plan and operational variables applicable to volunteer } \\
\text { fulfilment in non-profit driven organizations. Discoveries indicate that fulfilled } \\
\text { volunteers are bound to stay longer with the same establishment, give } \\
\text { monetarily to the non-profit driven organization, and prescribe the volunteer } \\
\text { involvement to other people. Every one of these results guarantees } \\
\text { the continuous sustenance of the non-profit driven establishment. }\end{array}$} \\
\hline Received Oct 29, 2019 & \\
\hline Revised Dec 28, 2019 & \\
\hline Accepted Feb 12, 2020 & \\
\hline Keywords: & \\
\hline Charity fundraising & \\
\hline Mobile apps & \\
\hline Social media & \\
\hline Social networking & \\
\hline
\end{tabular}

This is an open access article under the $\underline{C C B Y-S A}$ license.

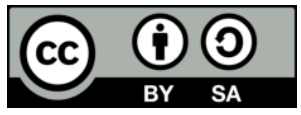

Corresponding Author:

Salama A. Mostafa,

Faculty of Computer Science and Information Technology,

Universiti Tun Hussin Onn Malaysia, Johor, Malaysia.

Email: salama@uthm.edu.my

\section{INTRODUCTION}

Practically $50 \%$ of all grown-ups in the United States volunteered time to non-profit establishments, giving more than 15 billion hours of volunteer time [1]. They filled in as unpaid service workers, frequently in brief positions, for example, build ing a home for Habitat for Humanity or serving food at a destitute home, and in addition, in semi representative limits, for example, carrying out authoritative obligations in libraries or medical clinics. Given the money related and operational structure of magnanimous non-profit driven establishments, it is obvious that many, if not most, couldn't work successfully in the absence of volunteers. Be that as it may, in spite of their duties as part of the workforce in and for these establishments, volunteers are one of a kind in numerous parts of delivering services. Their inspirations for volunteering will, in general, be more charitable than material gains or instrumental [2]. Since a volunteer does not get compensated by a non-profit driven association, in determining a volunteer's significant worth in the relationship is not the same as an employee. In numerous regards, volunteers in service delivery can like wise be seen as clients since they are utilizing the non-profit establishment to reach their own aims and targets. They are practically equivalent to clients in that they take an interest and can leave whenever they choose to [3].

The aim of this investigation is to look at the reliability chain of volunteers in service delivery inside non-profit driven establishments. In so doing, it establishes the framework to all the more likely comprehend 
the operational ramifications of structuring and overseeing charitable non-profit driven service establishments that depend intensely on volunteer work. The study utilizes the service profit chain as a beginning stage to visualize the preconditions that must be set up inside the working methodology of frame works in delivering services to develop a cycle of volunteer steadfastness and serviceability [1]. From this viewpoint, this exploratory study can be seen as an expansion of linkage study depicted as an inquiry that distinguishes those components of the workplace that are associated or related, with significant organizational results as well as consumer fulfilment and money-related operation [4].

As mobile advancements come to be the standard, portable charity applications serve as a chance for application suppliers to pull in new clients and non-profit establishments as another and developing handout or charity point of supply. The best qualification between mobile aid (or philanthropy) applications and different kinds of contribution is that contributors can obliquely give cash to philanthropy at whatever point they utilize the elements of mobile charity applications $[3,5]$. More explicitly, benefactors or contributors can download the application and gain points/notches or cash for foundations utilizing different elements of applications, for example, strolling, running or bike riding, ads watching, call making or games participation. Mobile charity application suppliers give cash depending on clients' notches to non -profit organizations.

Determining the basic characteristics of mobile gift application is significant in light of the fact that those characteristics facilitate persistent interest and eventually leads to progressively communal esteems [6, 7]. Subsequently, the motivation behind this paper is to explore the components that influence individuals' continual interest in utilizing mobile charity applications. By using cause-associated market hypothesis, this examination recognizes four properties that affect clients' probability of continuous utilizing of their mobile charity applications $[8,9]$. At that point, we exactly examine the impacts of those propertie s by leading an online study. We expect that the outcomes of this examination will add to the mobile application study including a charity study. We like wise propose the significance of providing appropriate components in service and structure rules for mobile charity applications [10].

In the cycle of business, establishments get most of their income from service delivery and goods created in the form of commodities or merchandise. Non-profit is different because they have three other significant way of getting income However, there are four primary sources of income and it is summarized as the following:

a. Charges for Non-public (private) Section originated Services and products

- Enrollment levy and occasion/events coupons

b. Private or non-public donations

- Ordinary Individual Contributors

- Raising support or fund soliciting

- Collective/collaborative supporters or Sponsors

c. Government Aids

d. Charges for Government originated Services and produce.

This project proposes using mobile apps for organizing and facilitating charitable and voluntary works in Malaysia. The idea of the project appeared to provide a participatory service. On the first hand, it attracts entrepreneurs and associations by giving them the opportunity to identify themselves, the area of their interest, their latest activities, and announcing their needs. On another hand, it attracts volunteers and donors by helping them reach and search for associations and volunteer opportunities appropriate to their skills, interes ts, time and places. All can be done using an application, both running to the link between these agencies .

As the mobile application market expands and offers different utilities, portable gifts have improved by exploiting the benefits of portable applications. One of the most Accepted Manuscript 4 broadly included qualities of new kinds of mobile contribution applications is that individuals can take part in utilizing the capacity of the application as opposed to giving their cash by hand. While direct gifts create real costs, interest in an aberrant gift is practically free of charge to the user [11-18]. At the end of the day, users can give the tallies produced by the number of utilizations of mobile donation applications. Previous studies have demonstrated that aberrant gift makes acts of virtue effort less [18-27]. This study is portioned into eight areas with the first segment serves as an introduction, in the second section, the methodology has been illustrated. Whereas, the design of the proposed Charity Fundraising Information System (CFIS) and implementation stage and the snapshots are presented under the third section. Finally, the conclusion including a couple of recommendations for future endeavours.

\section{METHODS}

Philanthropy is beneficial and it assists numerous individuals globally in a variety of circumstances. The structure of the philanthropy centre data frame work is subject to the database. Web and mobile services utilize the database hosted in a cloud infrastructure. These structures include the following: 
- Web services are utilized to look for donors on the website.

- Mobile services: A Mobile application applies Mobile services to look for a contributor.

- Database: the database is hosted in a cloud infrastructure. Every data is utilized by mobile and web services. Appropriate revision of giver and accepter information is required.

- Client: The most important user in the structure of the framework is the patient/acceptor. The patient/acceptor accesses the Data of a giver at whatever point necessary/required. Every needed data is checked completely.

The essential objective of the philanthropy system is to interconnect all the philanthropy social affairs or groups of the state into a single framework, endorsement, accumulating and flow of various live data and information by using measurement technologies. Such a system can accumulate all of the data of each and every person into decipherable records to assist in essential administration from feasible donor screening to perfect philanthropy distribution in the domain. The data which is taken care of on the calculation devices assists the general society easily access the status of philanthropy accessibility in a system with the intent of putting forward a solicitation or explicitly telling philanthropy units near to philanthropy centre (Especially unprecedented groups) save a beneficial life. The term philanthropy giving establishment suggests a location where the stored philanthropy is utilized to decrease the peril of transfusion events. Figure 1 shows the framework of the Charity Fundraising Information (CFIS) system.

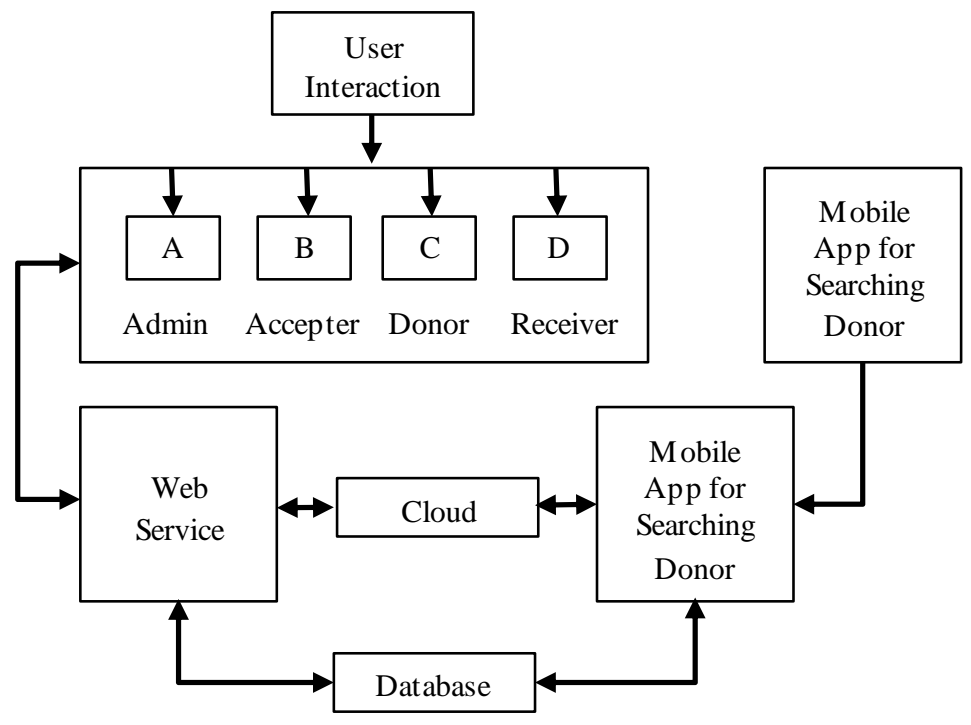

Figure 1. The framework of the CFIS

The current philanthropy contribution establishment gives uncommon ID to donors to track records of sponsor and notwithstanding recoup the giver's information whenever needed in the future. This process is especially dreary as time is a fundamental variable as a result of the quick transient nature of philanthropy and certain scenarios need philanthropy in a short time in the midst of such essential conditions. Further, the records are stored in large inventories [25, 27-29].

Among many of the social media, Facebook, Twitter, and Instagram are the most common applications that provide service for the charity. Also, it is providing new ways for nonprofits to engage the community in fundraising efforts [23]. Furthermore, online donors are prone to contribute to certain categories of causes more than others, especially those related to health. Given the growth in social media-driven fundraising and the increase in crowdfunding, slacktivism, impulse donating, and other new practices this entails these findings carry notable theoretical and practical implications [19]. Figure 2 shows the architecture of the donor and needy and how they communicate during the social media by the mobile Apps.

Moreover, Sixty-four percent of the organizations are blogging, showing no significant change from last year. Ninety percent of those studied in 2010 report social media is very important to increase awareness of their mission [27, 30]. While these organizations are best known for their non-profit status and their fundraising campaigns, they demonstrate an acute awareness of the importance of online strategies in meeting their objectives [31]. 


\section{THE PROPOSED CHARITY FUNDRAIS ING INFORMATION SYSTEM (CFIS)}

The format of CFIS is as in Figure 2(a). The blood donation center data System application is developed utilizing Android studio. The application has elements like Donor Form, Receiver Form, Transactions, Statistics, Blood Group, etc. (Figure 2(b)). This enables clients to select a specific blood class and record. The accessibility of a similar blood group is given by the application.

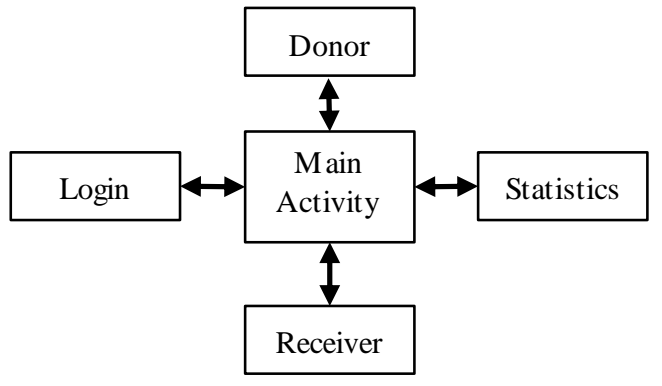

(a)

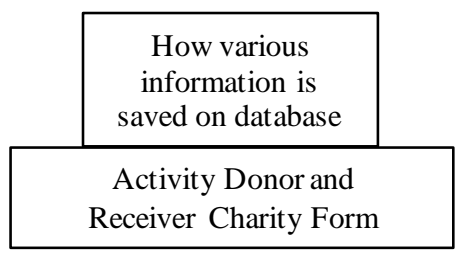

(b)

Figure 2. (a) Layouts and, (b) memory and activity interface

To benefit most from Android, one is required to exhibit the ability to re-factor and explore their applications to best use the auxiliary and developmental toolsets that Android studio has [19]. This assists the designers or developers to create, adminis ter and implement their applications, for instance, movement and feature entertainments. In the light of the observations, it very well may be derived that the android blood donation centre application has a remarkably vast domain and has tremendous whole potential and capacity in the field of vitality and embodiment. The blood donation centre data framework application is effectively finished and implemented.

The result of this application is notice and reaction from philanthropy/charity banks for philanth ropy respectively. The philanthropy bank has a database of the number of philanthropy packs for the separate philanthropy classes. On a low count, the framework will inform the experts and the App application is coordinated for the filling of the philanthropy providers. The smaller philanthropy donor application may likewise operate similarly, exactly when there any deficiency, the central bank is notified and the philanthropy is made accessible. The algorithm of the suggested work is referenced as follows. The information sources I and P are of character type. The steps are also explained pictorially with the help of the flow chart in Figure 3. The main phases are described as following:

- Phase 1: If client or user is enrolled, then provide User Id (I) and password (P) else Create new account;

- Phase 2: While philanthropy/charity stock gets low, Send notice to benefactors for blood gift camp;

- Phase 3: If there is demand from the client for blood, this shows in the database.

- Phase 4: Check for philanthropy accessibility at philanthropy bank;

- Phase 5: If philanthropy is unavailable, send notice from philanthropy bank to the enlisted Donors/Benefactors;

- Phase 6: Check conditions for a donation of blood, different variables and past his tory;

- Phase 7: If conditions are fulfilled acknowledge it;

- Phase 8: If Conditions are not fulfilled or appropriate, then send notice to different givers who are qualified;

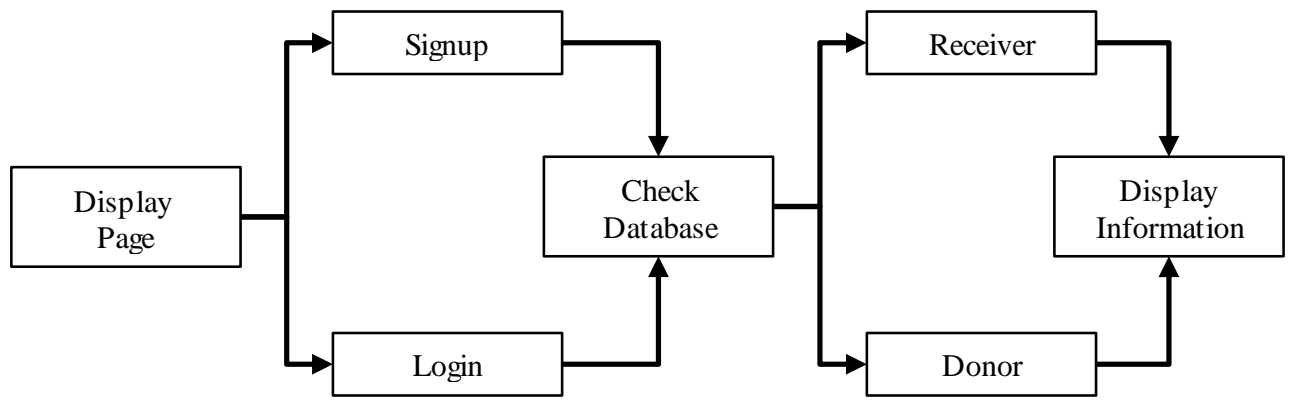

Figure 3. Flow Chart of the CFIS framework 
It is observable that the enrollment and contribution framework exceptionally influences the whole procedure but just a small percentage of the investigations are intended to expand these properties. There is a prerequisite of more appropriate evaluation and further research for this phase. The administration of the contributor's database remarkably affects the productivity of the whole procedure and their motivation. The operation of the frame work might be enhanced by expanding the number of gifts. Be that as it may, a viable administration of the enrolled contributor's database is necessary. Storage is additionally a significant phase of this procedure. An effective storage administration framework as in the case of blood donation must guarantee satisfactory coordination between the blood hold/move. It stores blood in ideal conditions and abstains from discharge and expiration. To anticipate and decrease obsolete blood bags and scarcity, the available blood donation centre models regularly depend on the examination of the standardized stock level. An incorporated administration methodology with blood information delivery may lead to increased productivity and efficiency.

In this study, the focus is placed on application improvement for mobile gadgets like cell phones utilizing accessible programming. The application created is appealing and valuable for clients having low gadget memory in applications. This application is compatible with any android 4.1 (Jellybean) versions and above. The primary benefits of the proffered application are expanded commitment and collaborations: This is capable of assisting the client with accessing the application so productively excluding any pop-ups, flags, ads and so on. The client may bring into operation their very own undertaking and at the same time can see the entire year exchange records. Immediate Access: Apps do not need a lot of time to open and carry out their assignments. One can gain access immediately.

Expanded or elevated security with existing frameworks: It stores every one of the information in a database which is confirmed the information and is observed throughout the months with no issue. More effective business procedures: Mobile applications provide speedy data and immediate help to clients constantly and wherever they required $[17,26]$. Furthermore, all important data are accessible on their cell phone tap away. Numerous new advances, for example, push alerts may likewise be delivered to their cell phones when new information or updates are on hand. The snapshots of implementation are illustrated in this section and described step by step as in the following: The fields are bound with appropriate approvals outlined as follows:

- The client requires creating an account.

- In the event that record is available, at that point login with client name and password.

- Show new and most appropriate opportunities in the newsfeed which are ranked depending on the client profile, utilizing a suggestion algorithm.

Include feedback about an activity that the client has officially joined (rate it, include a remark, share a post about the activity through the application on Facebook, and so forth.). Figure 4 shows the login and donor form as examples of the system interface, as presented in Table 1, which indicates the percentage of the giver in three scenarios (least, medium and greatest) and the outcomes areas in the table.

The greatest decrease in giving is by families between the ages of twenty and thirty. The proof demonstrates that younger family units are more averse to provide for philanthropy than much older ones. This is easy recognized by looking at age profiles over time. With the information exhibited along these lines, it is moderately clear to analyses or evaluates the conduct or behaviours of various date-of-birth associates. This is possible by beginning with any age-bracket in 1974 (ages 18-22 of 1974, for example) and following their conduct over the 20-year time frame through progressive age brackets (ages 23-27 of 1979, 28-32 of 1984, 33-37 of 1989 and 38-42 of 1993-94).

Figure 5 gives information about the percentage of charity or philanthropy contributors based on age. Furthermore, the red colour indicates the percentage of the philanthropy contributor or donor between ages 18-28 while the green colour serves to show the percentage of the philanthropy donor between ages 29-39. Additionally, the Purple colour serves to indicate the percentage of the philanthropy donor between ages 40-50. Further, the blue colour indicates the percentage of the philanthropy contributor in between ages 51-61. Finally, the orange shading portrays the percentage of the philanthropy contributor in between ages 72-82.

Table 1. The record of charitable processed via the mobile application

\begin{tabular}{ccccc}
\hline Figures & $\begin{array}{c}\text { Percentage } \\
\text { of donor }\end{array}$ & $\begin{array}{c}\text { Minimum } \\
\text { donation per week }\end{array}$ & $\begin{array}{c}\text { Medium donation } \\
\text { per week }\end{array}$ & $\begin{array}{c}\text { Maximum donation } \\
\text { per week }\end{array}$ \\
\hline $\begin{array}{c}\text { Total giving } \\
\text { Prompted }\end{array}$ & 29.1 & $\$ 1.23$ & $\$ 4.11$ & $\$ 5.35$ \\
Giving by standing order & 23.2 & $\$ 1.17$ & $\$ 3.80$ & $\$ 4.12$ \\
Giving by deduction form pay & 4.9 & $\$ 1.17$ & $\$ 4.84$ & $\$ 6.14$ \\
\hline
\end{tabular}




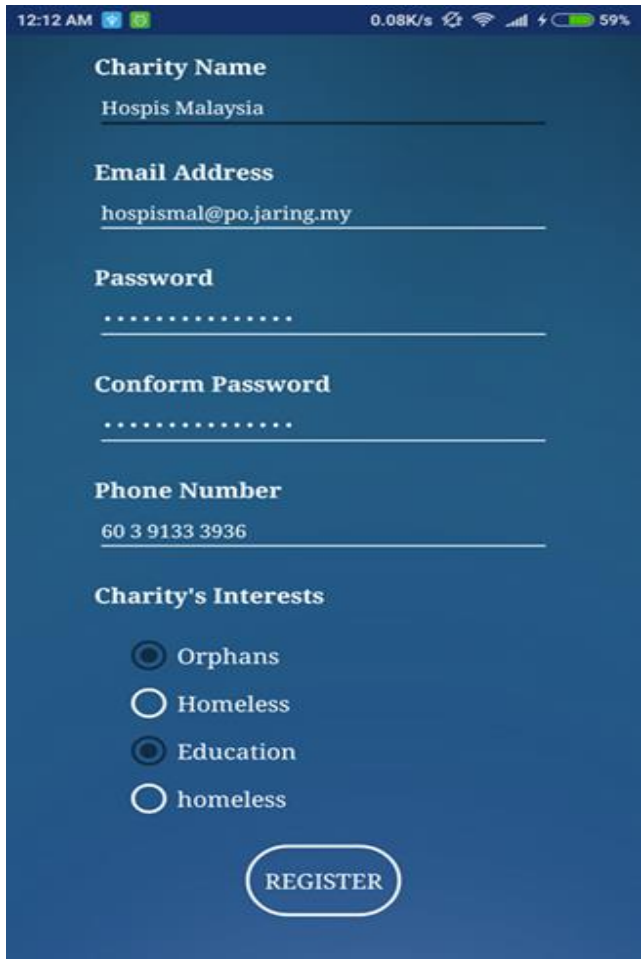

(a)

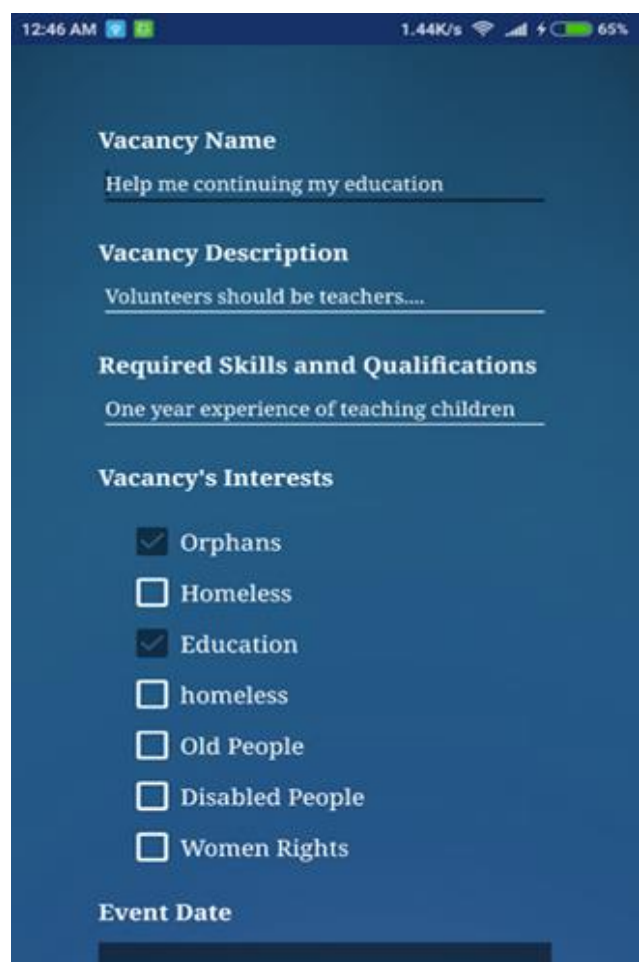

(b)

Figure 4. Snapshots of, (a) the login interface and, (b) the donor form

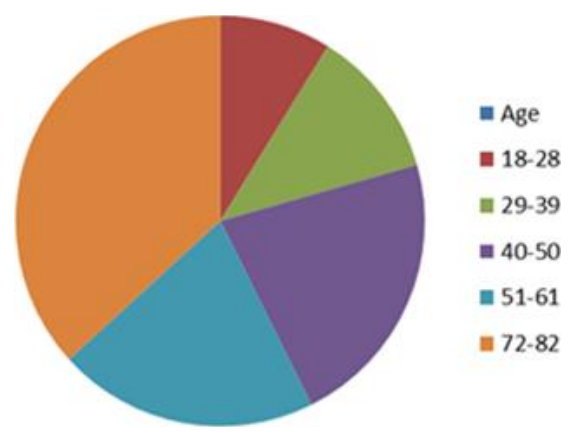

Figure 5. The percentage of the charity donor based on age

\section{CONCLUSION}

As mobile innovations come to be the standard, portable charity applications serve as a chance for application suppliers to pull in new clients and non-profit establishments as another and developing handout or charity point of supply. This archive presents the thought of propose and actualizes Charity Fundraising Information System (CFIS) that help to sort out philanthropy gifts. Past screen captures are only a model and the possibility of the application is profoundly expandable and versatile. The proposed interfaces are crude interfaces which intended to delineate the progression of occasions inside the application.

\section{ACKNOWLEDGEMENTS}

This work is sponsored by Universiti Tun Hussein Onn Malaysia under Tier 1 Vot number -H101.

\section{REFERENCES}

[1] J. C. Anderson and L. F. Moore, "The motivation to volunteer," Journal of Voluntary Action Research, vol. 7, pp. 120-129, 1978. 
[2] S. M. Farmer and D. B. Fedor, "Changing the focus on volunteering: an investigation of volunteers' multiple contributions to a charitable organization," Journal of Management, 2011, vol. 27, pp. 191-211.

[3] F. F. Reichheld and W. E. Sasser Jr. "Zero defections: quality comes to services," Harvard Business Review, vol. 68, pp. 105-111, 1990.

[4] S. D. Pugh, et al., "Driving service effectiveness through employee-customer linkages," Academy of Management Executive, vol. 16, pp. 73-85, 2002.

[5] Ang S. "Apps That fit charity into your daily routine," online available http://mashable.com/2014/01/01/charityapps-routine/\#, accessed on: 2014.

[6] Shestakova M., "Mobile apps for charity: Can technology make people more altruistic," Online avalble http://rstylelab.com/company/blog/mobile-technologies/mobileapps, accessed on: 2015.

[7] Garbett A., et al., "App movement: A platform for community commissioning of mobile applications," in Proc of the 16th CHI Conference on Human Factors in Computing Systems, San Jose, 2016, pp. 26-37.

[8] K. Han, et al., "Local News Chatter: Augmenting Community News by Aggregating Hyperlocal Microblog Content in a Tag Cloud," International Journal of Human-Computer Interaction, vol. 30, pp. 1003-1014, 2014.

[9] B. Larivie're, et al., "Value fusion: the blending of consumer and firm value in the distinct context of mobile technologies and social media," Journal of Service Management, vol. 24, pp. 268-293, 2013.

[10] M. Foth, et al., "Social and mobile interaction design to increase the loy alty rates of young blood donors," in Proc at the International Conference on Communities and Technologies, 2013.

[11] D. Yates and S. Paquette, "Emergency knowledge management and social media technologies: A case study of the 2010 Haitian earthquake," International Journal of Information Management, vol. 31, pp. 6-13, 2011.

[12] G. C. Shen, "Users' adoption of mobile applications: Product type and message framing's moderating effect," Journal of Business Research, vol. 68, pp. 2317-2321, 2015.

[13] J. I. Shin, et al., "The antecedents and consequency of user satisfaction of smartphone: The moderating effect of gender," Journal of Internet Electronic Commerce Research, vol. 14, pp. 203-220, 2014.

[14] J. Burrell, "Evaluating Shared Access: social equality and the circulation of mobile phones in rural Uganda," Journal of computer-mediated communication, vol. 15, pp. 230-250, 2010.

[15] J. Donner, "Research approaches to mobile use in the developing world: A review of the literature," The Information Society, vol. 24, pp. 140-159, 2008.

[16] A. Krishna, "Can supporting a cause decrease donations and happiness? The cause marketing paradox," Journal of Consumer Psychology, vol. 21, pp. 338-345, 2011.

[17] A. M. Eikenberry, "The hidden costs of cause marketing," Stanford Social Innovation Review, vol. 7, pp. 51, 2009.

[18] M. L. Shier and F. Handy, "Understanding online donor behavior: The role of donor characteristics, perceptions of the internet, website and program, and influence from social networks," International Journal of Nonprofit and Voluntary Sector Marketing, vol. 17, pp. 219-230, 2012.

[19] B. A. Khalaf, et al., "A Simulation Study of Syn Flood Attack in Cloud Computing Environment". AUS Journal, pp. 1-10, 2019.

[20] M. A. Muslim, et al., "Development of a quadruped mobile robot and its movement system using geometric-based inverse kinematics," Bulletin of Electrical Engineering and Informatics, vol. 8, no. 4, pp. 1224-1231, 2019.

[21] S. Quinton and P. Fennemore, "Missing a strategic marketing trick? The use of online social networks by UK charities," International Journal of Nonprofit and Voluntary Sector Marketing, vol. 18, no. 1, pp. 36-51, 2013.

[22] B. A. Khalaf, et al., "Comprehensive Review of Artificial Intelligence and Statistical Approaches in Distributed Denial of Service Attack and Defense Methods,”IEEE Access, vol. 7, pp. 51691-51713, 2019.

[23] B. A. Khalaf, "An adaptive model for detection and prevention of DDoS and flash crowd flooding attacks," in proc of the 3th International conference of Agent, Multi-Agent Systems and Robotics (ISAMSR), Putrajaya, pp. 1-6, 2018.

[24] M. H. Hassan, et al., "Integrating African Buffalo Optimization Algorithm in AODV Routing Protocol for improving the QoS of MANET,"Journal of Southwest Jiaotong University, vol. 54, 2019.

[25] M. Jubair and R. Muniyandi. "NS2 Simulator to Evaluate the Effective of Nodes Number and Simulation Time on the Reactive Routing Protocols in MANET." International Journal of Applied Engineering Research, vol. 11, no. 23, pp. 11394-11399, 2016.

[26] S. A. Mostafa, et al., "A Multi-Agent Ad Hoc On-Demand Distance Vector for Improving the Quality of Service in MANETs," in 2018 International Symposium on Agent, Multi-Agent Systems and Robotics (ISAMSR), pp. 1-7, August 2018.

[27] M. A. Jubair, et al., "Performance Evaluation of Ad-Hoc On-Demand Distance Vector and Optimized Link State Routing Protocols in Mobile Ad-Hoc Networks," International Journal on Advanced Science, Engineering and Information Technology, vol. 8, no. 4, 1277-1283, 2018.

[28] M. A. Jubair, et al., "A Survey of Multi-agent Systems and Case-Based Reasoning Integration," in 2018 International Symposium on Agent, Multi-Agent Systems and Robotics (ISAMSR), pp. 1-6, August 2018.

[29] M. H. Hassan, et al., "A hybrid algorithm for improving the quality of service in MANET," International Journal on Advanced Science, Engineering and Information Technology, vol. 8, no. 4, pp. 1218-1225, 2018.

[30] M. H. Hassan, et al., "A Survey of Multi-Agent System Approach in Risk Assessment," in 2018 International Symposium on Agent, Multi-Agent Systems and Robotics (ISAMSR), pp. 1-6, August 2018.

[31] M. E. Amran, et al., "Optimal distributed generation in green building assessment towards line loss reduction for Malay sian public hospital," Bulletin of Electrical Engineering and Informatics, vol. 8, no. 4, 2019. 